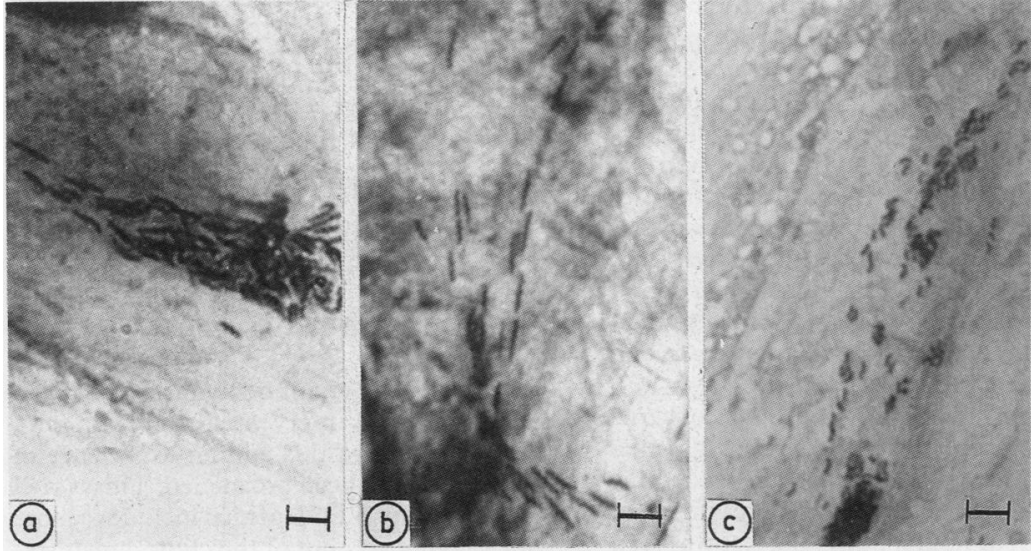

Gram stained smeared mucosa samples. ( $a$ and b) Tightly coiled spiral organisms in the two reported cases; (c) comparison of $C$ pylori organisms. Bar $=5 \mu \mathrm{m}$.

\section{Spiral shaped bacteria in gastric} mucosa

McNulty et al reported a tightly spiralled organism morphologically different from Campylobacter pylori in the gastric mucosa of some patients with upper abdominal symptoms. ${ }^{1}$ For this new spiral bacterium they suggested the name "Gastrospirillum hominis". We wish to report the observation of similar bacteria in two of the 210 patients who underwent gastroduodenal endoscopy for dyspepsia in Grosseto, Tuscany.

Five biopsy samples from each patient were taken from the gastric antrum and the edge of ulcers (when present), cultured on Columbia agar with $7 \%$ horse blood and the Skirrow mixture of chemotherapics, smeared and stained with the Gram stain and acridine orange, tested for the rapid urease activity, and examined histologically with haematoxylin and eosin stain.

In two cases in smeared mucosa samples we observed Gram negative, helical shaped organisms similar to those described by McNulty et al. ${ }^{1}$ The bacteria were numerous in one case (figure, a), and scarce in the other (figure, b), had two to five spirals, ranged in length from 3 to $7 \mu \mathrm{m}$, and were morphologically easily distinguishable from $C$ pylori (figure, c). Bacteria were also visible in smears stained with acridine orange. In one case the rapid urease test was positive within 15 minutes. No spiral organism grew after seven days of incubation in a microaerobic environment. Serology for $C$ pylori (as investigated by an ELISA according to Kaldor $e t$ $\left.a l^{2}\right)$ was negative for both patients.

The first patient, a 40 year old man, was asymptomatic. He had undergone endoscopy for a gastric ulcer two years earlier. He was treated with ranitidine and antacids. The endoscopy was negative, but the histological examination showed a glandular gastric hyperplasia. The second patient, a 78 year old woman, had mild nausea, epigastric discomfort, moderate chronic gastritis and eosophageal leucoplakia. She was not receiving any treatment.

Lee et al have recently isolated a spiralshaped bacterium from a cat's stomach which was morphologically similar to those seen by McNulty $e t a l^{1}$ and by us. The isolate was strongly urease, catalase, and oxidase positive. They also observed a tightly coiled spiral organism in the gastric biopsy specimens of two patients, and inferred that dogs (which also harbour spiral shaped micro-organisms in their stomach) and cats can transmit these bacteria to man.

The fact that these spiral shaped organisms have mostly been found associated with chronic gastritis may indicate that they represent a new group of primary pathogens for the gastric mucosa.

N FIGURA Istituto di Malattie Infettive, Università di Siena, I-53100 Siena S QUARANTA Servizio di Gastroenterologia, Divisione Medica $2 a$, Ospedale di Grosseto, I-58100 Grosseto,
Italy

1 McNulty CAM, Dent JC, Curry A, et al. New spiral bacterium in gastric mucosa. $J$ Clin Pathol 1989;42:585-91.

2 Kaldor J, Tee W, McCarty P, Watson J, Dwyer B. Immune response to Campylobacter pyloridis in patients with peptic ulceration Lancet 1985; ;:921.

3 Lee A, Hazel SL, O'Rourke JL, Kouprach S. Isolation of a spiral-shaped bacterium from the cat stomach. Infect Immum 1988;56 2843-50.

ducts and ductules. The precise nature of these concretions is uncertain and the factors responsible for liver disease in only a few patients with cystic fibrosis have not been clearly defined.' Two recent studies, however, reported that bile duct lesions may be a factor in the development of intrahepatic disease. Gaskin et al found evidence of biliary tract obstruction with stenosis of the distal common bile duct in 36 patients with sclerosing cholangitis in two of 50 patients with cystic fibrosis and hepatic disease ${ }^{2}$; a normal biliary tract was found in 31 control patients with no disease of liver disease. Strandwick et al reported that four of 102 patients with cystic fibrosis had ERCP evidence of scleros- ing cholangitis. ${ }^{3}$ The implications of these findings are that surgical intervention may prevent the onset or progression of the liver disease in cystic fibrosis; the cholangiolar dilatation may be due to bile duct obstruction, the inspissated concretions being a manifestation of the generalised abnormality of exocrine secretion which characterises mucoviscidosis.

$$
\begin{array}{r}
\text { RNM MACSWEEN } \\
\text { University Department of Pathology, } \\
\text { Western Infirmary, } \\
\text { Glasgow G11 6NT }
\end{array}
$$

1 Gaskin KJ, Waters DLM, Howman-Giles R, et al. Liver disease and common bile duc stenosis in cystic fibrosis. $N \mathrm{Engl} \mathrm{J} \mathrm{Med}$ $x x: 318: 340-6$

2 Strandvik B, Hjelte L, Gabrielsson N, Glaumann $\mathrm{H}$. Sclerosing cholangitis in cystic fibrosis. Scand J Gastroenterol 1988;23:121-4.

3 Hultcrantz R, Mengarelli S, Strandvick B. Morphological findings in the liver of children with cystic fibrosis: a light and electronmicroscopic study. Hepatology 1986;6:881-9.

\section{Intestinal microsporidiosis in AIDS}

We read with interest the letter by Lucas et al regarding the diagnosis of intestinal microsporidiosis in patients with AIDS. ${ }^{1}$ Although we agree that under ideal conditions appropriately stained microsporidia can be visualised at light microscopy, we are not of the opinion that this can be an absolutely confident diagnosis and feel that electron microscopical examination is essential, particularly in view of the paucity of experience in diagnosing these organisms.

Lucas et al state that, "cases of intestinal microsporidia may therefore be confidently identified by light microscopic examination, supplemented by electron microscopy," but in two of their three cases, which were from dewaxed material reprocessed for electron microscopic examination, only "probable spores" were seen. The fact is that in only one case have they "confidently" diagnosed microsporidia, and this was by electron microscopy, having already suspected the presence of microspondia by light microscopy. This may seem to be somewhat pedantic but confidence levels among histopathologists are extremely variable.

It is interesting that the microsporidia found by Lucas et al was consistent with Enterocytozoon bieneusi. ${ }^{2}$ Since the publication of our case ${ }^{3}$ the organism has also been identified as Enterocytozoon bieneusi by Professor E U Canning.

We feel that until diagnostic expertise is widely available in this field, it should be routine procedure to submit a part of the tissue from cases of AIDS immediately following biopsy for electron microscopy, so that definitive diagnoses can be made if such parasitic infection is suspected by light microscopy. Only then can we further our knowledge about this little known group of human infections.

$$
\begin{array}{r}
\text { LJ MCWILLIAM } \\
\text { A CURRY } \\
\text { University Department of Histopathology } \\
\text { University Hospital of South Manchester } \\
\text { Withington, Manchester }
\end{array}
$$
1 Diagnosis of intestinal microspondiosis in patients with AIDS. Lucas SB, Papadaki L, Conlon C, Sewinkambo N, Goodgame R, Serwadda D. J Clin Pathol 1989;42:885-7.

2 Desportes I, Le Charpentier Y, Galian A, et al. Occurrence of a new microsporidan Enterocytozoon bieneusi ng, nsp, in the Enterocytes of a human patient with AIDS J Protozool 1985;32:250-4.

3 Curry A, McWilliam LJ, Haboubi NY, Manda BK. Microsporidiosis in a British patient with AIDS. J Clin Pathol 1988;41:477-8. eosinophilic, periodic acid Schiff positive diastase resistant concretions in small bile microvesicular steatosis in cystic

Liver disease is common in patients with cystic fibrosis, the characteristic histological 